\title{
UCRL-JRNL-218979
}

LAW RENCE LIVERMORE N A T IO N A L LABORATORY

\section{Using Biofuel Tracers to Study Alternative Combustion Regimes}

J. H. Mack, D. L. Flowers, B. A. Buchholz, R. W. Dibble

February 14, 2006

Nuclear Instruments and Methods B 
This document was prepared as an account of work sponsored by an agency of the United States Government. Neither the United States Government nor the University of California nor any of their employees, makes any warranty, express or implied, or assumes any legal liability or responsibility for the accuracy, completeness, or usefulness of any information, apparatus, product, or process disclosed, or represents that its use would not infringe privately owned rights. Reference herein to any specific commercial product, process, or service by trade name, trademark, manufacturer, or otherwise, does not necessarily constitute or imply its endorsement, recommendation, or favoring by the United States Government or the University of California. The views and opinions of authors expressed herein do not necessarily state or reflect those of the United States Government or the University of California, and shall not be used for advertising or product endorsement purposes. 


\title{
Using Biofuel Tracers to Study Alternative Combustion Regimes
}

\author{
J.H. Mack ${ }_{\mathrm{a}}^{*}$, D.L. Flowers $\mathrm{b}$, B.A. Buchholz $\mathrm{c}_{\mathrm{c}}$, R.W. Dibble \\ a Combustion Analysis Laboratory, University of California Berkeley, Berkeley, CA 94720 USA \\ b Lawrence Livermore National Laboratory, Livermore, CA 94551 USA \\ c Center for Accelerator Mass Spectrometry, Lawrence Livermore National Laboratory, Livermore, CA \\ 94551 USA \\ * Corresponding Author: Univ. of California, Hesse Hall 50-B, Berkeley, CA 94720 USA Fax: 1-510-642- \\ 1850,Email: hmack@me.berkeley.edu
}

\subsection{Abstract}

Interest in the use of alternative fuels and combustion regimes is increasing as the price of petroleum climbs. The inherently higher efficiency of Diesel engines has led to increased adoption of Diesels in Europe, capturing approximately $40 \%$ of the new passenger car market. Unfortunately, lower $\mathrm{CO}_{2}$ emissions are countered with higher nitrogen oxides (NOx) and particulate matter (PM) emissions, and higher noise. Noise and PM have traditionally been the obstacles toward consumer acceptance of Diesel passenger cars in North America, while NOx (a key component in photochemical smog) has been more of an engineering challenge. Diesels are lean burning (combustion with excess oxygen) and reducing NOx to $\mathrm{N}_{2}$ in an oxygen rich environment is difficult. Adding oxygenated compounds to the fuel helps reduce PM emissions, but relying on fuel alone to reduce PM is unrealistic. Keeping peak combustion temperature below $1700 \mathrm{~K}$ prevents NOx formation. Altering the combustion regime to burn at temperatures below the NOx threshold and accept a wide variety of fuels seems like a promising alternative for future engines. Homogeneous Charge Compression Ignition (HCCI) is a possible solution. Fuel and air are well mixed prior to intake into a cylinder (homogeneous charge) and ignition occurs by compression of the fuel-air mixture by the piston. HCCI is rapid and relatively cool, producing little NOx and PM. Unfortunately, it is hard to control since HCCI is initiated by temperature and pressure instead of a spark or direct fuel injection. We investigate biofuel HCCI combustion, and use intrinsically labeled biofuels as tracers of HCCI combustion. Data from tracer experiments are used to validate combustion modeling.

\subsection{Keywords}

Biofuels, Tracers, Combustion, HCCI, 14C

\subsection{Introduction}

3.1 Historical use of Tracers in Internal Combustion Engines 
The methods described below for tracing fuel component carbon in the emissions can be applied to any combustion system. Any molecule containing carbon can be labeled with $14 \mathrm{C}$. Although only recently applied to studies of engine combustion processes [1-5], the techniques for measuring the 14C concentrations of $\mathrm{PM}$ and $\mathrm{CO}_{2}$ by AMS are straightforward and routine.

The use of $14 \mathrm{C}$ tracers in combustion engines provides insight into a number of different processes. There has been a significant amount of interest in Diesel engines, and 14C-radiolabelled experiments have been used to study the relative contributions of parent and alkyl-PAC to diesel exhaust emissions [6-7]. Soot formation by labeled components in Diesel fuel have been examined using decay counting methods $[8,9]$.

In addition to looking at exhaust contributions from fuel components, there has been research on the contributions of engine oils to exhaust emissions [1]. Other studies focused on applying isotope tracing techniques to the study of engine wear and damage [10].

Recent applications have explored the use of isotope tracers in Homogeneous Charge Compression Ignition (HCCI) engines, which is explained further below [11].

\subsection{Homogeneous Charge Compression Ignition}

The Homogeneous Charge Compression Ignition (HCCI) engine has received renewed interest in recent years. In the past decade, several hundred papers have been published, largely in the literature of the Society of Automotive Engineers. A recent text reviews much of this literature [12]. HCCI engines have some features of both spark ignited (SI) engines and Diesel engines. HCCI engines, like SI engines, are generally premixed and very lean at fuel-air equivalence ratio, $\Phi,<0.5$; thus they produce very low NOx and particulate matter (PM) emissions. Yet, HCCI engines typically have high compression ratios, leading to high efficiency similar to that found in Diesel engines. In an SI engine, the combustion event is initiated by a spark, and the timing of the spark is routinely adjusted by an onboard computer called an electronic control unit (ECU). Similarly, the combustion event in a Diesel engine is initiated by injection of the Diesel fuel and the injection time and duration is variable. However, the HCCI engine does not have a spark plug or direct fuel injection; the combustion event occurs when the cylinder contents are hot enough (approximately 1000-1200 K) for a long enough time (order $\sim 1$ millisecond).

Many challenges remain to practical HCCI engines. One of the major challenges of HCCI is controlling the combustion timing. Combustion timing is defined as the crank angle at which $50 \%$ heat release occurs, often called CA50. Each stroke of the piston in the cylinder occurs over 360 crank angle degrees. The point of peak compression is called top dead center (TDC) and engine timings are referred to in times of degrees

after top dead center (ATDC).

Another issue for HCCI engines is that pressure rise occurs very rapidly, because autoignition occurs nearly simultaneously throughout the combustion chamber. This rapid pressure rise can lead to noise, and potentially damaging knocking conditions within the engine. Avoiding detrimental effects of rapid pressure rise can limit the power output of HCCI engines.

\subsection{Approach and Motivations}

Better understanding of the HCCI combustion process can be greatly aided by evaluation of the chemical processes occurring in the combustion process, such as the effect of chemistry on combustion timing. It is possible to observe combustion characteristics of the fuel-in-air charge by collecting exhaust samples at different combustion timing.

Combustion timing is determined by a number of different parameters, such as equivalence ratio, intake manifold pressure, and intake manifold temperature. The primary influence of combustion timing is the intake manifold temperature $\left(T_{i n}\right)$ of the fuel-in-air mixture inducted into the engine combustion chamber. 
Devices such as electrical heaters, heat exchangers, and exhaust gas recirculation (EGR) control the HCCI engine intake temperature.

The composition of the fuel also plays a major part in the ignition process, as different fuels possess different autoignition characteristics. Autoignition is controlled by the rate of reaction between the fuel and oxidizer components. For a general reaction of

$$
F+v O x \stackrel{k}{\rightarrow} \operatorname{Pr}
$$

where $F$ is the fuel component, $O x$ is the oxidizer component, $P r$ is the products, and $k$ is the rate of reaction, which can be expressed as

$k=A T^{n} \exp \left(\frac{-E_{A}}{R T}\right)$

where $E_{A}$ is activation energy, $A$ is the pre-exponential constant, and $n$ is the temperature dependence. Each of these parameters can be associated with the autoignition properties of the fuel. Therefore, the autoignition properties of the fuel-in-air charge inside the engine combustion chamber can manipulated through the use of different fuels. With this in mind, blending fuels with different properties can yield small changes in combustion timing. Using fuel components with different $14 \mathrm{C}$ isotope ratios, we can see differences in the source of exhaust carbon dioxide composition, that is how much of each fuel component is converted to the $\mathrm{CO} 2$, which varies based on the fuel component characteristics and the combustion history of the fuel blend-in-air mixture.

\subsection{Experimental Objectives}

The rapid combustion event in HCCI presents a major engineering challenge, resulting in a pressure rise rate that can exceed $10 \mathrm{bar} / \mathrm{ms}$, which exceeds the material limits of the rings on a piston engine (J. Hiltner and S. Fiveland, personal communication, June 2003). One strategy to spread out the combustion event is to use a blend of two or more fuels that have different autoignition characteristics. The goal is that each fuel would burn in succession and thus spread out the combustion event duration, termed heat release elongation (HRE), which would help overcome the problem of too rapid rate of pressure rise. Examples of this fuel blending strategy include using dimethyl ether (easy to autoignite) mixed with methane (difficult to autoignite) [13], naptha with methane [14], and octane with n-heptane [15].

Furthermore, addition of fuel more prone to autoignition (low autoignition temperature) lowers the intake temperature required for HCCI operation. Intake temperature is typically a slowly responding parameter, with lags associated with thermal inertia of the intake system used for heating the flowing gas. Small changes in temperature can dramatically affect CA50, so overshooting a target temperature can push the combustion into an unstable regime [16-18], which may be difficult to respond to quickly enough with an intake temperature control scheme. Combustion timing is considered the most important combustion controlled parameter to achieve safe and stable operation. The combustion event is typically defined as CA50, the time when $50 \%$ of the cumulative heat release has occurred [19].

In this paper, we explore the HCCI combustion of blends of diethyl ether (DEE, sometimes written as EtOEt) in ethanol (EtOH) with small amounts of the additive Di-Tertiary Butyl Peroxide (DTBP). Volatility and flammability properties of the fuel components from Material Data Safety Sheets (MSDS) at 1 atmosphere are listed in Table 1.

Table 1. Properties of the fuels used in the experimental blends

\begin{tabular}{|c|c|c|c|}
\hline $\begin{array}{c}\text { Property at } \\
\mathrm{T}=298 \mathrm{~K}, \mathrm{P}=1 \mathrm{~atm}\end{array}$ & DEE & EtOH & DTBP \\
\hline
\end{tabular}




\begin{tabular}{|c|c|c|c|}
\hline $\begin{array}{c}\text { Flash Point } \\
\text { (Celsius) }\end{array}$ & -45 & 13 & 6 \\
\hline $\begin{array}{c}\text { Vapor Pressure } \\
\text { (mm Hg) }\end{array}$ & 58.9 & 5.8 & 2.6 \\
\hline $\begin{array}{c}\text { Boiling Point } \\
\text { (Celsius) }\end{array}$ & 35 & 79 & 110 \\
\hline $\begin{array}{c}\text { Autoignition } \\
\text { Temperature } \\
\text { (Celsius) }\end{array}$ & 160 & 363 & 165 \\
\hline Specific Gravity & 0.789 & 0.71 & 0.79 \\
\hline
\end{tabular}

DEE autoignites more readily than ethanol. In earlier research, we observed that the autoignition of DEE leads EtOH in blends, but not as much as expected [20]. There was no significant elongation of the combustion event with DEE-EtOH blends [20]. The autoignition temperature of DTBP is similar to DEE, but DTBP experiences self accelerating (exothermic) decomposition at 80C. The exothermic decomposition of DTBP is a common property of organic peroxides.

The addition of DTBP to gasoline reduces the ignition delay time in HCCI Engines operating near idle [21]. DTBP is widely used as a catalyst for polymerization of olefin copolymers and crosslinking agent for unsaturated polyesters. It is also used as an ignition improver for increasing cetane number in diesel engines [22-24]. Our intention was to use the exothermic decomposition DTBP to elongate the combustion event by igniting the DEE earlier.

Because of the greater reactivity of DEE, we anticipated that DEE would autoignite first followed by autoignition of $\mathrm{EtOH}$, which might be determined if the contribution of each fuel component to the $\mathrm{CO} 2$ in the engine exhaust could be measured. Determining the source of $\mathrm{CO}_{2}$ produced by each fuel requires a means of distinguishing the sources of the carbon. Using bio-derived EtOH that has a natural carbon-14 (14C) level and petroleum-derived DEE and DTBP that are free of $14 \mathrm{C}$, we could distinguish the contribution of EtOH to $\mathrm{CO}_{2}$ by measuring its isotopic content.

Table 2. Caterpillar 3401 Engine Specifications

\begin{tabular}{|l|l|}
\hline Configuration & $\begin{array}{l}\text { Single } \\
\text { Cylinder }\end{array}$ \\
\hline Valves & $\begin{array}{l}4(2 \text { int., } 2 \\
\text { exh.) }\end{array}$ \\
\hline Compression Ratio & 16.25 \\
\hline Displacement & $2.44 \mathrm{~L}$ \\
\hline $\begin{array}{l}\text { Camshaft Lobe Lift } \\
\text { (Exhaust) }\end{array}$ & $8.796 \mathrm{~mm}$ \\
\hline $\begin{array}{l}\text { Camshaft Lobe Lift } \\
\text { (Intake) }\end{array}$ & $8.113 \mathrm{~mm}$ \\
\hline
\end{tabular}

The experiments were conducted in a single cylinder Caterpillar 3401 engine, the specifications of which are in Table 2. The engine was maintained at constant speed of $1800 \mathrm{RPM}(+/-10 \mathrm{rpm})$ by an induction motor/generator. Intake temperatures were changed using an electrical heater located 1 meter upstream of the engine. Liquid fuel injectors, mounted 0.75 meters upstream to insure complete vaporization of the fuel, controlled the equivalence ratio.

\subsection{Experimental Procedure}

Experiments were conducted for HCCI engine operation conducted with mixtures of ethanol with DEE and DTBP. The equivalence ratios, $\Phi$, of 0.3 and 0.4 were used in the experiment. High loads were not investigated due to the nature of HCCI engines and previous research done on DTBP which points to more effectiveness at lower loads [16]. The intake pressure was held at a constant $\mathrm{P}=1.7$ bar. Grain ethanol 
(EtOH) served as the tracer (bio-derived, contains 14C) fuel while diethyl ether (DEE) and DTBP are petroleum-derived fuels (14C free). The isotopic level of the lubrication oil and DEE was at instrument background $(14 \mathrm{C} / \mathrm{C}$ ratios $<10 \mathrm{E}-15)$. Since the ethanol is bio-derived, it is uniformly labeled with $14 \mathrm{C}$; each of the two carbon atoms in the ethanol molecule is equally likely to be $14 \mathrm{C}$.

The fuel blends containing DEE-in-EtOH were defined on a volume percent basis (for example, $250 \mathrm{~mL}$ DEE for every $750 \mathrm{~mL} \mathrm{EtOH}$ for the $25 \%$ DEE-in ethanol blend). With the addition of DTBP, the volume of DEE was maintained while the EtOH was reduced to accommodate the volume of DTBP.

Figure 1 shows the experimental set-up. Exhaust gas samples were collected at varying combustion timing for each fuel mixture. CA50 was controlled by adjusting the intake temperature. Exhaust gas routed from the exhaust manifold through a particulate filter and then collected in 3-L or 10-L Tedlar bags, which filled in less than a minute. No particulate matter was observed on the particulate filter.

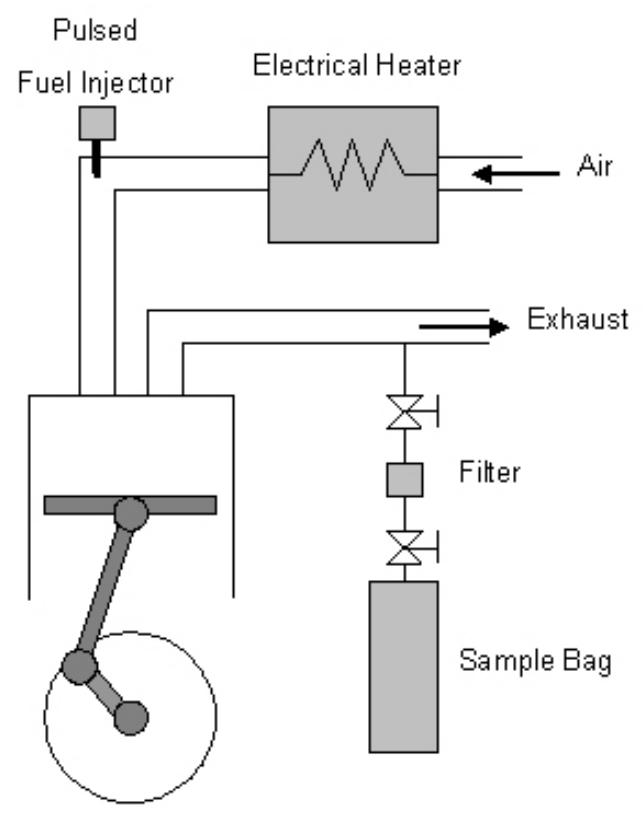

Figure 1. Experimental set-up for exhaust collection from the single cylinder CAT3401 engine. Note that the fuel is introduced after the intake heater and well upstream $(\sim 1 \mathrm{~m})$ of the engine so as to insure thorough mixing and evaporation.

The gas sample bags were maintained at temperatures between $290-300 \mathrm{~K}$ and processed within several days of collection. Bags were equilibrated with an evacuated $\sim 60 \mathrm{~mL}$ volume to obtain AMS samples containing 0.2-1.1 mg C from separated $\mathrm{CO}_{2}$. All gas molecules except $\mathrm{N}_{2}$ and $\mathrm{CO}$ were initially condensed with a liquid nitrogen (LN) cold trap. This first cold trap was then switched to dry iceisopropanol so water, sulfur dioxide, and unburned fuel were retained and second cold trap with LN was placed in series to condense $\mathrm{CO}_{2}$. A valve between the traps was closed and non-condensable gases were evacuated. The $\mathrm{CO}_{2}$ was then cryogenically transferred to a quartz sample tube which was sealed with a $\mathrm{H}_{2} / \mathrm{O}_{2}$ torch. Each purified $\mathrm{CO}_{2}$ sample was then transferred to our graphitization rig where it passed through another dry ice-isopropanol cold trap and was condensed again with LN. Carbon mass was determined from $\mathrm{CO}_{2}$ pressure in a small fixed volume before transfer to an individual reactor and reduction to graphite in the presence of iron catalyst [25]. All graphite targets were measured at the center for AMS at LLNL using 6 identically prepared oxalic acid standards for normalization [26].

Only the ethanol contains a significant $14 \mathrm{C}$ signal in this system. Backgrounds associated with sample prep are known and the contribution of intake air to the exhaust $\mathrm{CO}_{2}$ is subtracted. Expanding the $14 \mathrm{C} / \mathrm{C}$ ratio to show the remaining terms for each sample produces a simple expression where $C$ and $R$ denote carbon mass and isotope ratio and the subscripts ${ }_{E}$ and ${ }_{D}$ denote ethanol and DEE+DTBP, respectively (Eq.3). 


$$
R_{s}=\frac{C^{14}{ }_{E}}{C_{E}+C_{D}}=\frac{C_{E}\left(R_{E}\right)}{C_{E}+C_{D}}
$$

The fraction of ethanol-derived carbon $F_{E}$ in the sample is given in Equation 4.

$$
F_{E}=\frac{C_{E}}{C_{E}+C_{D}}=\frac{R_{S}}{R_{E}}
$$

\subsection{Numerical Modeling Approach}

Simulations of HCCI combustion of the diethyl-ether-in-ethanol blend have been conducted using a "single-zone" numerical model of the engine. This single-zone model treats the cylindrical combustion chamber as a spatially uniform reactor with uniform temperature, pressure, and composition throughout. The reactor volume changes based on slider-crank relations that determine the motion of the piston in an engine cylinder. The simulation handles only the closed part of the cycle; intake and exhaust processes are not considered.

In the single zone, conservation of energy and chemical kinetic relations based on a gas-phase detailed kinetic mechanism for diethyl-ether and ethanol combustion are solved to determine temperature and species histories for the engine cycle.

The DEE/EtOH chemical mechanism contains an extension of that for dimethyl ether [27] with diethyl ether chemistry provided by Curran [28] and a mechanism of EtOH [29]. The combined mechanism contains 112 species and 484 reactions. Additional reactions for the adiabatic decomposition of DTBP were added into the mechanism, following the work of Iizuka et al [30].

In the simulation, DTBP is seen to thermally decompose into two t-butoxy radicals, in the $600-650 \mathrm{~K}$ temperature range.

$\left(\mathrm{CH}_{3}\right)_{3} \mathrm{COOC}\left(\mathrm{CH}_{3}\right)_{3} \rightarrow\left(\mathrm{CH}_{3}\right)_{3} \mathrm{CO} \bullet+\left(\mathrm{CH}_{3}\right)_{3} \mathrm{CO} \bullet$

These radicals internally rearrange very quickly; primarily forming acetone $\left(\mathrm{CH}_{3} \mathrm{COCH}_{3}\right)$ and a methyl radical $\left(\cdot \mathrm{CH}_{3}\right)$.

$\left(\mathrm{CH}_{3}\right)_{3} \mathrm{CO} \cdot \rightarrow \mathrm{CH}_{3} \mathrm{COCH}_{3}+\cdot \mathrm{CH}_{3}$

The acetone is stable and lingers in the cycle until the main ignition promoting reactions commencing at temperatures of approximately $1100 \mathrm{~K}$. It is tempting to assign the advance in combustion timing to the presence of $\cdot \mathrm{CH}_{3}$ attacking the main fuels and commencing radical chain reactions, including chain branching. However, close examination of the simulation shows that the ${ }^{-} \mathrm{CH}_{3}$ radicals formed remain are relatively stable species do not significantly contribute to the chain propagation and chain branching reactions that lead to ignition. After the formation of these relatively stable species, little chemistry is taking place; the temperature is still too cold. Importantly, the formation of these relatively stable species is exothermic. The more important effect on ignition resulting from these "low-temperature reactions" associated with decomposition of DTBP is a slight increase in the temperature that is amplified by further compression of the mixture. For this thermal reason (as opposed to direct kinetic reasons) addition of DTBP leads to advancement of CA50 timing at constant input temperature; or equivalently, a reduction of input temperature if the same CA50 timing is desired.

The single-zone model is a highly idealized representation of the actual processes occurring in the combustion chamber. Models exist, e.g. KIVA, that that have thousands of zones and thus capture in more detail the three-dimensional processes occurring in the combustion chamber [13,31-32], such as crevice and 
boundary layer effects. Still, single-zone models can give insight into the processes occurring in the combustion chamber, especially processes that occur in the hottest central core gasses of the combustion chamber away from the crevice and boundary layers. It has been shown in the literature that a single zone model is effective in predicting engine behavior versus experimental data for HCCI engines [33].

A multiple-zone model would provide more detailed results but at a high computational cost. In this case, a single-zone model is effective in predicting system behavior primarily due to the homogeneous mixture found in HCCI engines. Diesel and SI engines are inherently more difficult to model due to the inhomogeneities found in the combustion chamber, and would not be well simulated with this type of model. In contrast, HCCI engine combustion can be well represented by this single-zone approach.

Important to accurate prediction with a single-zone model is inclusion of heat transfer [34-37] and trapped residuals in the model. Simulations were conducted using the geometric and operating parameters for the engine specified in Table 1 .

\subsection{Results}

When analyzing the results provided by the isotope tracing, parameter called zeta $(\zeta)$ was defined. Zeta, defined in Equation 5, is the fraction of $14 \mathrm{C}$ in exhaust $\mathrm{CO}_{2}$ normalized to the $14 \mathrm{C}$ fraction of the fuel.

$\xi=\frac{\left(F_{E t O H}\right)_{\mathrm{CO}_{2}}}{\left(F_{E t O H}\right)_{F U E L}}$

When zeta equals 1, all of the EtOH in the fuel blend is burning to completion. Likewise, when the value of zeta is zero, none of the $\mathrm{EtOH}$ in the fuel blend is burning to completion.

Figure 2 shows variation of zeta for three different fuel blends of varying amounts of the DEE blended with $\mathrm{EtOH}$, with respect to the combustion timing.



Figure 2. Zeta, the mass fraction EtOH in $\mathrm{CO} 2$ normalized to fuel, for three fuels mixtures. Error bars assume $1 \%$ uncertainty in fuel concentration. The uncertainty in the fuel shifts the whole series up or down (the accuracy). However, the precision is unchanged.

Figure 2 shows that as the amount of DEE in the fuel blend is increased, more of the EtOH burns to completion. The top two lines show data for two different loads (phi equal to 0.3 and 0.4 ) but with the same blend composition. As more fuel is added to the mixture (higher values of phi), the overall heat 
release is greater and the combustion event provides more power. The limiting factor in adding fuel to gain power is mechanical considerations (risk of engine damage).

Figure 3 shows variation of zeta for fuel blends containing the additive DTBP in 25\% DEE in EtOH blends (25DEE) with respect to combustion timing.

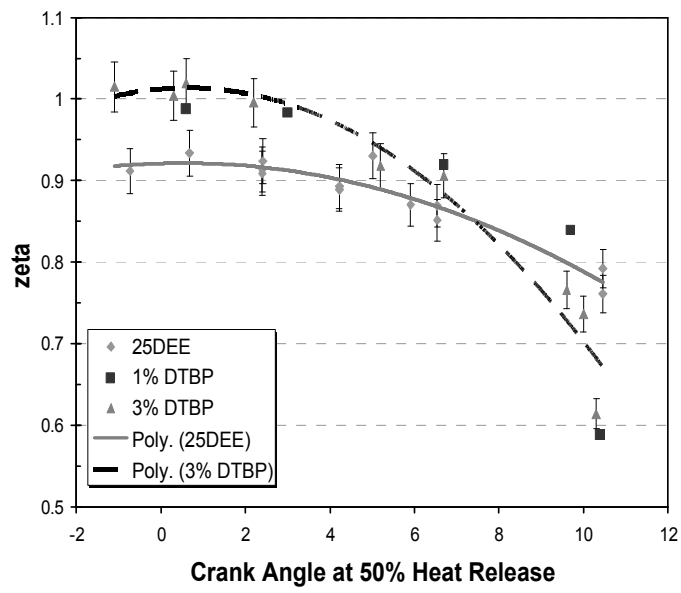

Figure 3. The addition of DTBP to DEE/EtOH blends causes more EtOH to burn to completion

The addition of DTBP causes the EtOH in the fuel blend to burn even further to completion. Experimental data sets for fuel blends containing DTBP approach zeta values of 1 while the 25DEE blend by itself does not approach complete combustion.

Figure 4 shows exhaust gas emissions data for the base fuel blend of 25DEE. The increase of carbon monoxide (CO) and unburned hydrocarbons $(\mathrm{HC})$ at later combustion timings confirms less complete combustion. Data for exhaust nitric oxide emissions is not shown in the figure but was extremely low $(\sim 5$ ppm) as expected with HCCI combustion.

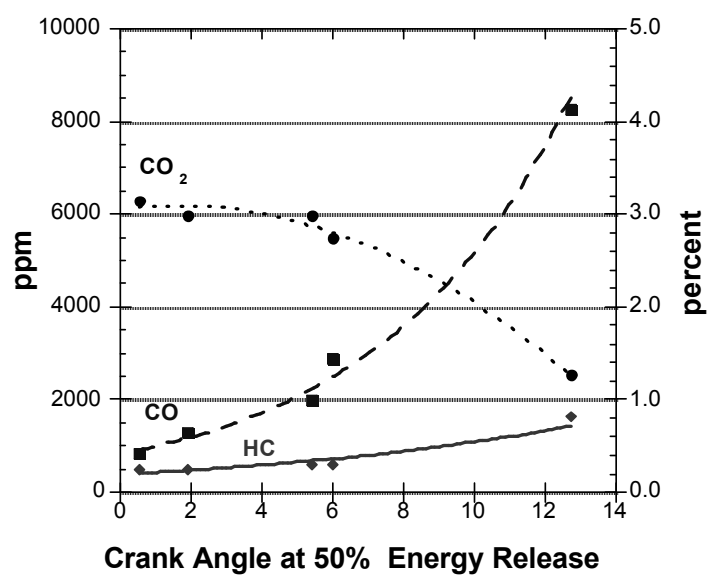

Figure 4. Gas analyzer data for $25 \% \mathrm{DEE}$ in EtOH at $\Phi=0.4$; $\mathrm{CO}$ (in percent), decreases as CA50 is delayed, while $\mathrm{CO}$ and $\mathrm{HC}$ (in ppm) increases.

Figure 5 shows the numerical modeling results for fuel blends (25DEE), with and without the DTBP additive. The crank angle for $90 \%$ combustion (CA90) of a fuel component remains unchanged for EtOH 
in both cases (1\% and 3\% DTBP) but the CA90 for DEE is slightly earlier, especially for later combustion timings.

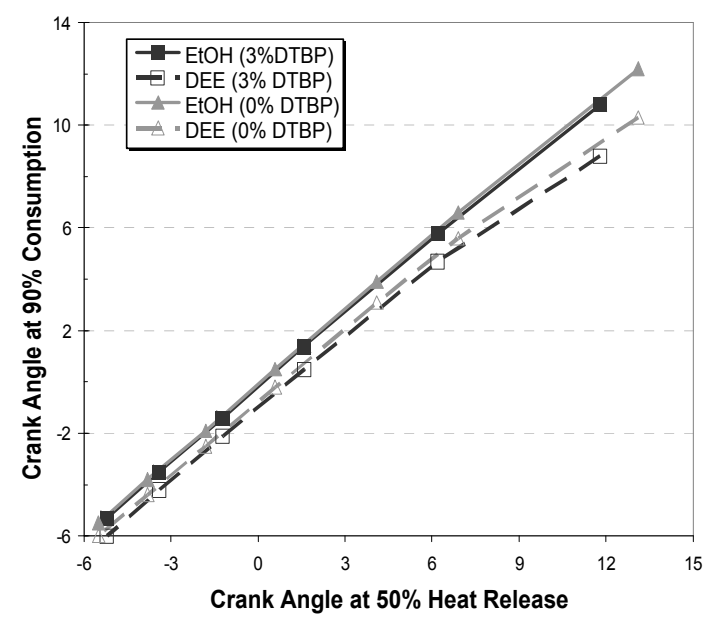

Figure 5. The addition of DTBP to 25DEE/EtOH causes the DEE to burn earlier in the cycle, especially at later combustion timings.

The two-stage combustion event discussed in the motivations would show a drastic difference in CA90 for the fuel blend components but the difference seen in Fig.5 is around 1 CAD. Not until the latest combustion timings (after $9 \mathrm{CAD}$ ) does the CA90 of DEE significantly precede the EtOH CA90. Experimentally, we are unable to obtain these latest combustion timings due to the increased sensitivity to heat transfer.

Figures 6 and 7 show the intake temperature (in Kelvin) versus the combustion timings (CA50, crank angle for $50 \%$ heat release) for experimental and numerical results, respectively.



Figure 6. Experimental results for the Intake Temperature (Kelvin) versus the Crank Angle at 50\% Heat Release (CA50) 




Figure 7. Numerical Modeling results for the Intake Temperature (Kelvin) versus the Crank Angle at $50 \%$ Heat Release (CA50)

One of the major advantages for HCCI combustion when using DTBP is the decrease in required intake temperature for start of combustion. This is shown in both the experimental and numerical modeling figures. As the amount of DTBP is increased, the required intake temperature at a given CA50 is significantly reduced.

\subsection{Conclusions}

HCCI presents many advantages (i.e. low NOx, low PM, and high efficiency) not seen in the traditional engine, but there are still many obstacles to overcome before it is a commercially viable alternative. Through the use if $14 \mathrm{C}$ isotope tracers, we are able to gain further insight into the combustion characteristics of fuel blends inside the engine. In this set of experiments, the data shows that Ethanol burns further to completion with addition of Diethyl Ether and Ditertiary Butyl Peroxide. Through the use of a single-zone model, numerical results provided additional information on the behavior of the fuel blends during combustion.

The intake temperature required for start of combustion (as defined by CA50, the crank angle of $50 \%$ heat release) was observed to decrease dramatically with the addition of DTBP to all fuel blends. Numerical modeling was able to show this trend for all operating conditions.

Although an elongation of the heat release was not observed for these particular fuel blends, it is possible that through the use of isotope tracing we will be able to identify fuel blends that display the kind of behavior that will help in balancing out the barriers to practical deployment of HCCI engine technology.

\subsection{Acknowledgements}

This project is funded by the Department of Energy Office of FreedomCAR and Vehicle Technologies (Steve Goguen and Gurpreet Singh, Program Managers) the DOE University HCCI Program, and LLNL Laboratory Directed Research and Development grant 01-ERI-007. This work was performed in part under the auspices of the U.S. Department of Energy by University of California Lawrence Livermore National Laboratory under Contract No. W-7405-Eng-48.

\subsection{References}

[1] B.A. Buchholz, A.S. Cheng, R.W. Dibble, C.J. Mueller, and G.C. Martin, "Isotopic Tracing of Fuel Component Carbon in the Emissions from Diesel Engines" SAE Technical Paper 2002-01-1942, SAE Trans. 111, 927-938, 2002. 
[2] A.S. Cheng, R.W. Dibble, and B.A. Buchholz, "The Effect of Oxygenates on Diesel Engine Particulate Matter" SAE Technical Paper 2002-01-1705, 2002.

[3] B.A. Buchholz, A.S. Cheng, and R.W. Dibble, "Isotopic Tracing of Bio-Derived Carbon from Ethanol-in-Diesel Blends in the Emissions of a Diesel Engine" SAE Technical Paper 2002-01-1704, 2002.

[4] A.S. Cheng, B.A. Buchholz, and R.W. Dibble, "Isotopic Tracing of Fuel Carbon in the Emissions of a Compression-Ignition Engine Fueled With Biodiesel Blends" SAE Technical Paper 2003-01-2282, SAE Trans. 112, 2015-2020, 2003.

[5] B.A. Buchholz, R.W. Dibble, D. Rich, and A.S. Cheng, "Quantifying the contribution of lubrication oil carbon to particulate emissions from a diesel engine" SAE Technical Paper 2003-01-1987, SAE Trans. 112, 1874-1879, 2003.

[6] C.J. Trier, M.M. Rhead, and D.E. Fussey, "Evidence for the pyrosynthesis of parent polycyclic aromatic compounds in the combustion chamber of a diesel engine" Conference Proceedings for IMechE Automotive Power Systems - Environment and Conservation, Paper C394/003, 1990.

[7] C.J. Trier, D.E. Fussey, D. Ryder, and M.A. Graham, "Development of radiotracer techniques for diesel fuel and exhaust emission research" Conference Proceedings for IMechE Automotive Power Systems - Environment and Conservation, Paper C433/010, 1991.

[8] H.S. Homan and W.K. Robbins, "A Carbon-14 Tracer Study of the Relative Fractions of Various Fuel Carbons in Soot" Combustion \& Flame 63:177-190, 1986.

[9] M.M. Rhead, D.E. Fussey, C.J. Trier, G.S. Petch and D. Wood, "Investigation of the Fate of Specific Hydrocarbon Fuel Components in Diesel Engine Combustion" Science of the Total Environment 93:207-214, 1990.

[10] D.C. Eberle, M.B. Treuhaft, and Z. Tao, "The Use of Radioactive Tracer Technology to Evaluate Engine Wear Under the Influences of Advanced Combustion System Operation and Lubricant Performance" SAE Technical Paper 2005-01-3689, 2005.

[11] J.H. Mack, D.L. Flowers, B.A. Buchholz, and R.W. Dibble, "The Effect of the Di-Tertiary Butyl Peroxide (DTBP) Additive on HCCI Combustion of Fuel Blends of Ethanol and Diethyl Ether" SAE Technical Paper 2005-01-2135, 2005.

[12] F. Zhao, Homogeneous Charge Compression Ignition (HCCI) Engines: Key Research and Development Issues. SAE International, USA, 2003.

[13] D. Flowers, S. Aceves, J.R. Smith, J. Torres, J. Girard, and R. Dibble, "HCCI in a CFR Engine: Experiments and Detailed Kinetic Modeling," SAE Paper 2000-01-0328. 2000.

[14] R.H. Stanglmaier, T.W. Ryan III, and J.S. Souder, "HCCI Operation of a Dual-Fuel Natural Gas Engine for Improved Fuel Efficiency and Ultra-Low NOx Emissions at Low to Moderate Engine Loads." SAE Technical Paper 2001-01-1897, 2001.

[15] M. Christensen, B. Johansson, and P. Einewall, "Homogeneous Charge Compression Ignition Using Isooctane, Ethanol and Natural Gas - A Comparison with Spark Ignited Operation." SAE Paper No. 972874.

[16] P. Flynn, G. Hunter, A. zur Luye, O. Akinyemi, R. Durrett, G. Moore, J. Mudd, G. Muntean, J. Wagner, J. Wright. "Premixed Charge Compression Ignition Engine with Optimal Combustion Control." US Patent 6,286,482 B1. 2001.

[17] P. Flynn, G. Hunter, A. zur Luye, O. Akinyemi, R. Durrett, G. Moore, G. Muntean, L. Peters, P. Pierz, J. Wagner, J. Wright, J. Yeager. "Premixed Charge Compression Ignition Engine with Optimal Combustion Control.” US Patent 6,276,334 B1. 2001.

[18] A. zur Loye, O. Akinyemi, R. Durrett, P. Flynn, G. Hunter, G. Moore, J. Mudd, G. Muntean, J. Wagner, J. Wright. "Premixed Charge Compression Ignition Engine with Optimal Combustion Control." US Patent 6,230,683 B1. 2001.

[19] R. Stone, Introduction to Internal Combustion Engines (3rd Edition). SAE International, USA, 1999.

[20] J.H. Mack, D.L. Flowers, B.A. Buchholz, and R.W. Dibble, "Investigation of HCCI Combustion of Diethyl Ether and Ethanol Mixtures Using Carbon 14 Tracing and Numerical Simulations," Proceedings of The Combustion Institute, Vol 30/2 pp 2693-2700, 2004.

[21] J.A. Eng, W.R. Leppard, and T.M. Sloane, "The Effect of Di-Tertiary Butyl Peroxide (DTBP) Addition to Gasoline on HCCI Combustion," SAE Technical Paper 2003-01-3170, 2003.

[22] Liotta, F. J., "A Peroxide Based Cetane Improvement Additive With Favorable Fuel Blending Properties”, SAE Technical Paper, No. 932767 (1993). 
[23] Goto, S., Lee, D., Wakao, Y., Honma, H., Mori, M., Akasa, Y., Hashimoto, K., Motohashi, M., and Konno, M., " Development of an LPG DI Diesel Engine Using Cetane Number Enhancing Additives", SAE Technical Paper, No. 1999-01-3602 (1999).

[24] Alam, M., Goto, S., Sugiyama, K., Kajiwara, M., Mori, M., Konno, M., Motohashi, M., and Oyama, K., "Performance and Emissions of a DI Diesel Engine Operated With LPG and Ignition Improving Additives", SAE Technical Paper, No. 2001-01-3680 (2001).

[25] J.S. Vogel, J.R. Southon, and D.E. Nelson, "Catalyst and Binder Effects in the Use of Filamentous Graphite for AMS" Nucl. Instrum. Methods Phys. Res. Sect. B v29, 1987, pp.50-56.

[26] M.L. Roberts, G.S. Bench, T.A. Brown, M.W. Caffee, R.C. Finkel, S.P.H.T. Freeman, L.J. Hainsworth, M. Kashgarian, J.E. McAninch, I.D. Proctor, J.R. Southon, and J.S. Vogel, "The LLNL AMS Facility" Nucl. Instru. Meth. B, v123, 1997, pp.57-61.

[27] H.J. Curran, W.J. Pitz, C.K. Westbrook, P. Dagaut, J.-C. Boettner, and M. Cathonnet, "A Wide Ranging Study of Dimethyl Ether Oxidation," International Journal of Chemical Kinetics, 1998. 30(3): p. 229-241.

[28] H.J. Curran, "Reaction Mechanism for Oxidation of Diethyl Ether," to be submitted. 2005.

[29] N.M. Marinov, "A Detailed Chemical Kinetic Model for High Temperature Ethanol Oxidation," International Journal of Chemical Kinetics 31:183-220, 1999.

[30] Y. Iizuka and M. Surianarayanan, "Comprehensive Kinetic Model for Adiabatic Decomposition of Di-tert-butyl Peroxide Using BatchCAD,” Ind. Eng. Chem. Res. 2003, 42, 2987-2995.

[31] D.L. Flowers, S.M. Aceves, C.K. Westbrook, J.R. Smith, and R.W. Dibble, "Detailed Chemical Kinetic Simulation of Natural Gas HCCI Combustion: Gas Composition Effects and Investigation of Control Strategies," ASME J. of Eng. Gas Turb. Power, 2001. 123: p. 433-439.

[32] D.L. Flowers, "Combustion in Homogeneous Charge Compression Ignition Engines: Experiments and Detailed Chemical Kinetic Modeling," PhD Dissertation, UC Davis, 2001.

[33] S. B. Fiveland and D. N. Assanis, "Development and Validation of a Quasi-Dimensional Model for HCCI Engine Performance and Emissions Studies under Turbocharged conditions", SAE Technical Paper 2002-01-1757, 2002.

[34] G. Woschni, "Universally Applicable Equation for the Instantaneous Heat Transfer Coefficient in the Internal Combustion Engine," SAE Paper 670931, SAE Trans., vol. 76, 1967.

[35] G. Woschni and J. Fieger, "Experimental Investigation of the Heat Transfer at Normal and Knocking Combustion in Spark Ignition Engines," MTZ, vol. 43, 1982.

[36] K. Sihling and G. Woschni, "Experimental Investigation of the Instantaneous Heat Transfer in the Cylinder of a High Speed Diesel Engine," SAE paper 790833, 1979.

[37] J.B. Heywood, Internal Combustion Engine Fundamentals. McGraw-Hill. New York, NY, USA. 1988. 